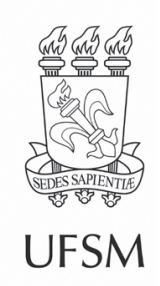

\title{
Artigos
}

\section{Estrutura da comunidade arbórea e efeito de borda em Florestas Estacionais Semideciduais}

\author{
Structure of the arboreal community and edge effect in Semidecidual \\ Seasonal Forests
}

\section{Vanuza Pereira Garcia da Silva' ${ }^{\bullet}$, Gabriel Venâncio Pereira Mariano' ${ }^{\circ}$, Ana Flávia Costa Santos" $"$, Lilian Cristina da Silva Santos ${ }^{\bullet}$, $^{\circ}$ João Paulo Costa"l' ${ }^{\oplus}$, Ana Carolina Ribeiro Vaz ${ }^{\oplus}$, Vagner Santiago do Vale ${ }^{\bullet}$, Ednaldo Cândido Rocha'®}

\author{
'Universidade Estadual de Goiás, Ipameri, GO, Brasil \\ "Universidade Estadual do Sudoeste da Bahia, Vitória da Conquista, BA, Brasil \\ '"Universidade Federal de Uberlândia, Uberlândia, MG, Brasil
}

\section{RESUMO}

Efeito de borda são modificações ambientais que, por sua vez, alteram a estrutura e a composição da vegetação marginal em uma floresta. Assim, o objetivo deste estudo foi verificar o comprimento, em metros, da faixa exposta ao efeito de borda em dois fragmentos de Floresta Estacional Semidecidual. $O$ trabalho foi executado em duas áreas distintas. Em ambas as áreas foram plotadas 30 parcelas de $10 \mathrm{x}$ $10 \mathrm{~m}$, demarcadas a partir da borda florestal, dispostas em três transectos, nos quais foram amostrados e identificados todos os indivíduos com circunferência a 1,30 m de altura e diâmetro $\geq 15 \mathrm{~cm}$. Para a avaliação da abrangência florística do método e suficiência amostral, foi elaborada a curva espécieárea, baseada na distância em relação à borda e calculada a regressão que melhor se ajustou à curva. Em seguida, dois dendrogramas de similaridade foram elaborados, baseados na presença/ausência das espécies em cada parcela e no número de indivíduos por parcela. No total, foram amostrados 955 indivíduos arbóreos. A curva espécie-área de um dos locais de estudo estabilizou a partir dos $40 \mathrm{~m}$, indicando que nesta faixa não houve aparecimento de novas espécies. No entanto, a curva retomou aumento a partir de $50 \mathrm{~m}$. Na outra área, a estabilização na riqueza das parcelas ocorreu a $60 \mathrm{~m}$ da borda, com aumento no surgimento de novas espécies a $70 \mathrm{~m}$. Em uma das áreas avaliadas, o efeito de borda atingiu $30 \mathrm{~m}$ em direção ao interior da floresta, enquanto na segunda área avaliada, esta distância foi de $70 \mathrm{~m}$.

Palavras-chave: Curva espécie-área; Dendrograma de similaridades; Fitossociologia 


\section{ABSTRACT}

Edge effects are environmental settings that, in turn, alter the structure and composition of marginal vegetation in a forest. Thus, the objective of this study was to verify the length, in meters, in the strip exposed to the edge effect in two fragments of the Seasonal Semideciduous Forest. The report was carried out in two different areas. In such areas, 30 plots of $10 \times 10 \mathrm{~m}$ were plotted, demarcated from the floral border, arranged in three transects, where all individuals with a circumference at $1.30 \mathrm{~m}$ in height and diameter $\geq 15 \mathrm{~cm}$ were sampled and cut. For an evaluation of the floristic scope of the method and the sampling sufficiency, a curve of specific area was elaborated, based on the distance in relation to the border and the regression that best fits the curve was calculated. Then, two similarity dendrograms were prepared, based on the presence/absence of species in each plot and the number of plots per plot. In total, 955 tree isolates were sampled. An area curve of one of the study sites stabilized after $40 \mathrm{~m}$ shows that there were no new species in this range. However, a curve resumed an increase from $50 \mathrm{~m}$. In another area, the richness stabilization of the plots occurred at $60 \mathrm{~m}$ from the edge, with an increase in new species at $70 \mathrm{~m}$. In one of the evaluated areas, the edge effect reached $30 \mathrm{~m}$ towards the interior of the forest, while in the second evaluated area, the distance was $70 \mathrm{~m}$.

Keywords: Species-area curve; Dendrogram of similarity; Phytosociology

\section{INTRODUÇÃO}

O processo de fragmentação está entre os fatores responsáveis pela redução da biodiversidade (SEOANE et al., 2010). Fragmentos são áreas de vegetação contínua que se transformam em pequenos remanescentes florestais, isolados um dos outros e com grandes alterações na paisagem, podendo reduzir-se a um habitat de borda (HADDAD et al., 2015).

As interações dos processos ecológicos nos fragmentos estão ligadas diretamente à distância das perturbações ocorridas desde a borda para o interior da floresta (BLUMENFELD et al., 2016). Conforme esse efeito avança para o interior do fragmento, é possível prever o quanto de área conservada existe no interior ou área núcleo, que é a área que não sofre o efeito de borda (MAGNAGO et al., 2016). Dessa forma, pode-se supor que quanto mais irregular e menor for o fragmento, maior será a área de contato com a matriz, e maior o efeito de borda.

As mudanças estruturais da vegetação, distribuição, riqueza, abundância e diversidade, são comumente alteradas pelo efeito de borda (OLIVEIRA et al., 2013). A caracterização da vegetação próxima da borda é de exemplares de menor porte, 
o que permite uma maior penetração da luz, vertical e horizontal, e também de água da chuva no solo, devido ao menor volume foliar, estimulando a germinação e crescimento de espécies, sendo estas geralmente pioneiras (PSCHEIDT et al., 2018). A disponibilidade de luz tende a diminuir a intensidade à medida que se aproxima do interior do fragmento e, consequentemente, há uma redução na exposição das plantas menores à luz, o que interfere no seu crescimento (RIGUEIRA et al., 2012).

Outro efeito de borda é a presença de lianas, ou trepadeiras. Essas espécies se beneficiam da baixa umidade presente perto da borda de fragmentos florestais, desenvolvendo-se com mais rapidez nestas condições, tornando-se fortes competidoras com as árvores presentes próximas da borda, interferindo no crescimento e desenvolvimento de frutos (ALMEIDA; VIANI; BRANCALION, 2017). Devido ao seu desenvolvimento estar sob a copa das árvores, essa ação resulta na quebra dos ramos, configurando estresse ao indivíduo arbóreo e prejudicando sua permanência (ABDO; VALERI; FERRAUDO, 2015).

As interações dos processos ecológicos nos fragmentos estão ligadas diretamente à distância das perturbações ocorridas desde a borda para o interior da floresta (LAURANCE et al., 2002). Essas perturbações podem atingir centenas de metros para dentro da floresta (LAURANCE et al., 2011), sendo que os primeiros $30 \mathrm{~m}$ são os que mais sofrem os impactos (RIGUEIRA et al., 2012). Conforme o efeito avança para o interior do fragmento, é possível prever o quanto de área conservada, área que não sofre com o efeito, existe no interior ou área núcleo (LAGOS, 2017). Supõe-se, portanto, que, quanto mais irregular e menor for o fragmento, maior será a área de contato com a matriz, e maior o efeito de borda.

No Cerrado ocorrem as florestas estacionais semideciduais (FES), formação florestal considerada remanescente de Mata Atlântica em ambientes sazonais (COSTA; GUASSELLI, 2017). Os remanescentes de florestas estacionais existentes em Goiás aparecem frequentemente fragmentadas e distantes na paisagem dominada por pastagens e agricultura (PEREIRA; VENTUROLI; CARVALHO, 2011) e devem estar sob ação do efeito de borda. Dessa maneira, o objetivo deste estudo foi verificar em até quantos metros adentro da floresta, o efeito de borda afeta a vegetação arbórea para dois fragmentos de FES. 


\section{MATERIAIS E MÉTODOS}

O estudo foi realizado em duas áreas distintas de Floresta Estacional Semidecidual. A primeira área (A1) era um fragmento de 53 hectares de área total, localizado em propriedade rural no município de Ipameri-Goiás (coordenadas

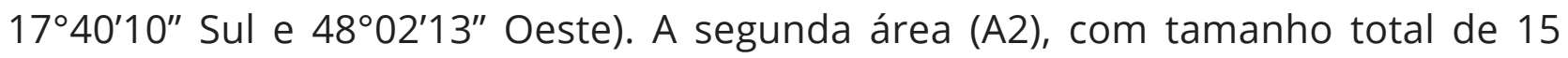
hectares, corresponde à área de vegetação nativa da fazenda da Universidade Estadual de Goiás, também em Ipameri-GO (coordenadas $17^{\circ} 42^{\prime} 44^{\prime \prime}$ Sul e de $48^{\circ} 08^{\prime}$ 22" Oeste). A distância entre os fragmentos era de 10,87 km. As imagens aéreas dos dois remanescentes estão na Figura 1.

Figura 1 - Visão aérea e posição das parcelas nos fragmentos analisados

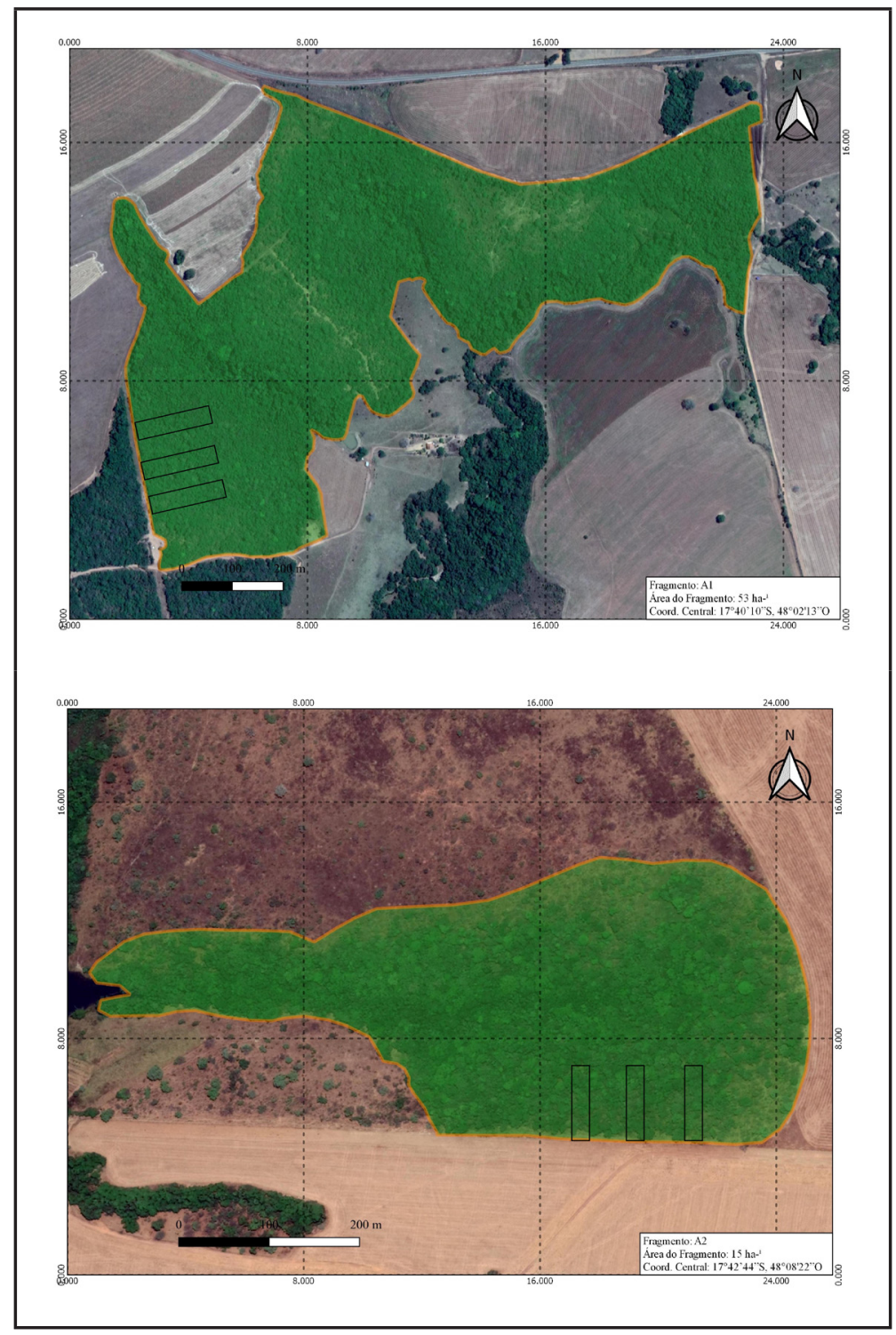

Fonte: Autores (2018) 
Em ambos os estudos, foram amostrados 3 transectos com 10 parcelas contíguas permanentes de 10×10 m cada, demarcadas a partir da borda florestal (Figura 1) com estacas de ferro e fita barbante, totalizando 0,3 ha amostrados por área. A distância entre cada transecto foi de, no mínimo, 50 metros, medidos a partir da linha de referência, na parte externa do fragmento.

A pluviosidade média anual da região é de $1.531 \mathrm{~mm}$, distribuída irregularmente, com verão quente e chuvoso de outubro a março e médias de $219 \mathrm{~mm}$ mensais, e inverno seco de abril a setembro com médias de $36 \mathrm{~mm}$ mensais. A temperatura média anual varia entre $20.2^{\circ} \mathrm{C}$, no inverno, e $22.9^{\circ} \mathrm{C}$ no verão (ALVARES et al., 2014). Segundo a classificação de Köppen, essas características climáticas se enquadram no tipo tropical quente e úmido (Aw). O solo da região é classificado como Latossolo Vermelho-amarelo com textura argilosa, segundo o Sistema de Classificação de Solos (SANTOS et al., 2018).

Em cada parcela foram registrados, amostrados e identificados com placa de alumínio enumerada, todos os indivíduos arbóreos vivos com circunferência a altura do peito, 1,30 m (CAP) $\geq 15 \mathrm{~cm}$. A altura foi estimada com auxílio de um podão de coleta de $14 \mathrm{~m}$. Todos os indivíduos foram classificados em espécies e famílias de acordo com o sistema do Angiosperm Phylogeny Group IV (CHASE et al., 2016). A identificação das espécies foi realizada diretamente em campo ou com coleta de material botânico e confecção de exsicatas para identificação por outros especialistas.

Para a avaliação da abrangência florística do método e suficiência amostral, foi elaborada a curva espécie-área (SCHILLING; BATISTA; COUTO, 2012), baseada na distância em relação à borda e calculada a regressão que melhor se ajustou à curva. Também foram calculadas a suficiência amostral de área basal e a quantidade de indivíduos para as duas áreas. Neste trabalho, para se validar os dados obtidos quanto à suficiência amostral, o erro de amostragem admissível (E\%) foi $\leq 20 \%$.

Os parâmetros fitossociológicos analisados foram: densidade relativa (DeR), dominância relativa (DoR) e frequência relativa (FrR), que são utilizados na composição 
do valor de importância (VI) para espécies. Foram calculados os índices de ShannonWeaver $\left(\mathrm{H}^{\prime}\right)$, que leva em consideração a riqueza das espécies e sua abundância relativa (LIMA; SOUZA; PEDERASSI, 2016), e equitabilidade de Pielou (J'). Os indivíduos sem identificação botânica foram retirados dessas análises para não sobrevalorizar os índices. Este último é um índice de uniformidade que se refere ao padrão de distribuição dos indivíduos entre as espécies (BIONDI; BOBROWSKI, 2014).

As parcelas foram unidas baseando-se em suas distâncias com relação à borda, e, em seguida, foram elaborados dois dendrogramas de similaridade, o primeiro baseado na presença/ausência das espécies em cada parcela (Coeficiente de Sørensen) e o segundo baseado no número de indivíduos por parcela (Índice de Bray \& Curtis), utilizando o software PAST 3 (HAMMER, 2019).

Para averiguar se fatores abióticos exerciam interferências na borda ou no interior da floresta, foram aferidos os valores de umidade do ar (\%), temperatura $\left({ }^{\circ} \mathrm{C}\right)$, velocidade do vento $(\mathrm{km} / \mathrm{h})$ e a intensidade da luz (lux) nas épocas chuvosa (fevereiro/2019) e seca (setembro/2019). As análises foram realizadas somente na área 2 (A2) e as medições foram realizadas em três horários, com intervalos de 3 horas. O primeiro horário de medição era às $10 \mathrm{~h}$, depois às $13 \mathrm{~h}$ e a última medição era realizada às $16 \mathrm{~h}$. Nas parcelas plotadas em A2, eram selecionados no horário das medições três pontos casuais para que as variáveis fossem medidas. Foram adotadas distâncias de 5, 15, 25, 35, 45, 55, 65, 75, 85 e 95 m da borda. Com os dados obtidos, foram calculadas as regressões com as variáveis medidas em relação à distância da borda.

\section{RESULTADOS E DISCUSSÃO}

Em A1, foram amostrados 504 indivíduos (1.713 ind/ha), distribuídos em 35 famílias e 68 espécies, sendo que 22 indivíduos não foram identificados por estarem sem folha, ultrapassarem a altura da tesoura aérea de poda e/ou não ser possível a coleta botânica. A maioria das espécies encontradas foi classificada como secundárias 
iniciais (27 espécies) e pioneiras (23), totalizando $81,96 \%$ do valor total. Os índices de diversidade de Shannon $\left(\mathrm{H}^{\prime}\right)$ e de equitabilidade de Pielou (J) foram 3,58 e 0,85, respectivamente.

A área basal total amostrada foi de $7,02 \mathrm{~m}^{2}\left(23,41 \mathrm{~m}^{2} /\right.$ ha $)$ e as espécies que apresentaram maior densidade foram: Myracrodruon urundeuva (9,33\%); Myrsine gardneriana (7,34\%); Cordiera sessilis (6,94\%); Sclerolobium paniculatum (4,37\%); Qualea grandiflora (4,37\%), Terminalia glabrescens. (4,17\%) e Pera glabrata (3,77\%). Essas sete espécies foram responsáveis por 32\% da densidade total das da amostra, sendo um pequeno número de espécies responsáveis por maior parte da densidade da floresta (Tabela 1). Outras 48 espécies obtiveram até 5 indivíduos, apresentando as menores densidades, sendo 25 dessas espécies com apenas 1 indivíduos amostrado (Tabela 1).

Tabela 1 - Lista florística e parâmetros fitossociológicos de espécies identificadas em um fragmento de floresta estacional semidecidual, denominado Área 1 (A1), em propriedade rural no município de Ipameri-GO

\begin{tabular}{lcccccc}
\hline \multicolumn{1}{c}{ Espécies } & N. Ind. & DeR & DoR & FrR & IVI\% & GS \\
\hline Myracrodruon urundeuva Allemão & 47 & 9,33 & 10,60 & 5,25 & 8,39 & ST \\
Myrsine gardneriana A. DC. & 37 & 7,34 & 7,18 & 5,57 & 6,70 & P \\
Sclerolobium paniculatum Vogel & 22 & 4,37 & 7,69 & 4,55 & 5,53 & P \\
Licania apetala (E. Mey.) Fritsch & 28 & 5,56 & 6,24 & 4,22 & 5,34 & SI \\
Pera glabrata (Schott) Poepp. ex Baill. & 19 & 3,77 & 7,45 & 2,60 & 4,61 & P \\
Cordiera sessilis (Vell.) Kuntze & 34 & 6,75 & 2,05 & 4,87 & 4,56 & SI \\
Não identificadas & 22 & 4,37 & 3,34 & 4,22 & 3,97 & - \\
Qualea grandiflora Mart. & 22 & 4,37 & 2,58 & 4,87 & 3,94 & ST \\
Anadenanthera peregrina (L.) Speg. & 14 & 2,78 & 4,90 & 3,57 & 3,75 & SI \\
Emmotum nitens (Benth.) Miers & 16 & 3,17 & 3,49 & 3,57 & 3,41 & ST \\
Terminalia glabrescens Mart. & 20 & 3,97 & 1,98 & 3,90 & 3,28 & SI \\
Xylopia aromatica (Lam.) Mart. & 15 & 2,98 & 2,26 & 4,55 & 3,26 & P \\
Diospyros brasiliensis Mart. ex Miq. & 17 & 3,37 & 2,36 & 2,92 & 2,89 & SI \\
Aspidosperma discolor A. DC. & 16 & 3,17 & 2,23 & 1,95 & 2,45 & ST \\
Magonia pubescens A. St.-Hil. & 12 & 2,38 & 1,85 & 2,27 & 2,17 & SI \\
Terminalia argentea Mart. \& Zucc. & 9 & 1,79 & 2,41 & 2,27 & 2,15 & SI \\
Tapirira guianensis Aubl. & 12 & 2,38 & 1,38 & 2,60 & 2,12 & SI \\
Siparuna guianensis Aubl. & 13 & 2,58 & 0,67 & 2,92 & 2,06 & SI
\end{tabular}


Tabela 1 - Continuação

\begin{tabular}{|c|c|c|c|c|c|c|}
\hline Espécies & N. Ind. & DeR & DoR & FrR & IVI\% & GS \\
\hline Tapirira obtusa (Benth.) J. D. Mitch. & 12 & 2,38 & 2,13 & 1,30 & 1,94 & SI \\
\hline Lamanonia ternate Vell. & 1 & 0,20 & 4,98 & 0,32 & 1,83 & SI \\
\hline Myrcia splendens (Sw.) DC. & 10 & 1,98 & 0,52 & 2,60 & 1,70 & $P$ \\
\hline Coccoloba mollis Casar. & 6 & 1,19 & 1,82 & 1,30 & 1,44 & SI \\
\hline Qualea parviflora Mart. & 2 & 0,40 & 2,94 & 0,65 & 1,33 & ST \\
\hline Virola sebifera Aubl. & 6 & 1,19 & 0,68 & 1,95 & 1,27 & $P$ \\
\hline Rhamnidium elaeocarpum Reissek & 6 & 1,19 & 0,45 & 1,62 & 1,09 & $P$ \\
\hline Platypodium elegans Vogel & 4 & 0,79 & 0,87 & 1,30 & 0,99 & SI \\
\hline Luehea grandiflora Mart. & 4 & 0,79 & 0,73 & 0,97 & 0,83 & $P$ \\
\hline Machaerium opacum Vogel & 3 & 0,60 & 0,93 & 0,97 & 0,83 & $P$ \\
\hline Guettarda viburnoides Cham. \& Schltdl. & 4 & 0,79 & 0,64 & 0,97 & 0,80 & SI \\
\hline Chrysophyllum gonocarpum (Mart. \& Eichler ex Miq.) Engl. & 3 & 0,60 & 0,70 & 0,97 & 0,76 & ST \\
\hline Aspidosperma subincanum Mart. ex A. DC. & 5 & 0,99 & 0,49 & 0,65 & 0,71 & SI \\
\hline Dimorphandra mollis Benth. & 3 & 0,60 & 0,53 & 0,97 & 0,70 & $P$ \\
\hline Curatella americana $\mathrm{L}$. & 3 & 0,60 & 0,50 & 0,97 & 0,69 & $P$ \\
\hline Roupala montana Aubl. & 3 & 0,60 & 0,50 & 0,97 & 0,69 & ST \\
\hline Diospyros hispida A. DC. & 4 & 0,79 & 0,52 & 0,65 & 0,66 & SI \\
\hline Sclerolobium aureum (Tul.) Baill. & 3 & 0,60 & 0,56 & 0,65 & 0,60 & $P$ \\
\hline Alibertia sessilis (Vell.) K. Schum. & 3 & 0,60 & 0,21 & 0,97 & 0,59 & SI \\
\hline Maytenus floribunda Reissek & 2 & 0,40 & 0,71 & 0,65 & 0,59 & ST \\
\hline Cecropia pachystachya Trécul & 2 & 0,40 & 0,62 & 0,65 & 0,56 & $P$ \\
\hline Pseudobombax tomentosum (Mart.) Robyns & 2 & 0,40 & 0,51 & 0,65 & 0,52 & SI \\
\hline Astronium fraxinifolium Schott & 1 & 0,20 & 0,98 & 0,32 & 0,50 & $\mathrm{SI}$ \\
\hline Styrax ferrugineus Nees \& Mart. & 2 & 0,40 & 0,53 & 0,32 & 0,42 & SI \\
\hline Cheiloclinium cognatum (Miers) A.C. Sm. & 2 & 0,40 & 0,19 & 0,65 & 0,41 & SI \\
\hline Chrysophyllum splendens Spreng. & 2 & 0,40 & 0,17 & 0,65 & 0,40 & ST \\
\hline Matayba guianensis Aubl. & 2 & 0,40 & 0,16 & 0,65 & 0,40 & SI \\
\hline Alibertia edulis (Rich.) A. Rich. & 2 & 0,40 & 0,07 & 0,65 & 0,37 & $P$ \\
\hline Hymenaea stigonocarpa Mart. ex Hayne & 2 & 0,40 & 0,32 & 0,32 & 0,35 & ST \\
\hline Ixora brevifolia Hiern & 3 & 0,60 & 0,12 & 0,32 & 0,35 & ST \\
\hline Bowdichia virgilioides Kunth & 1 & 0,20 & 0,34 & 0,32 & 0,29 & $P$ \\
\hline Symplocos nitens (Pohl) Benth. & 2 & 0,40 & 0,14 & 0,32 & 0,29 & SI \\
\hline Hirtella glandulosa Spreng. & 1 & 0,20 & 0,27 & 0,32 & 0,27 & $\mathrm{SI}$ \\
\hline Dilodendron bipinnatum Radlk. & 1 & 0,20 & 0,20 & 0,32 & 0,24 & $P$ \\
\hline Agonandra brasiliensis Miers ex Benth. \& Hook. f. & 1 & 0,20 & 0,16 & 0,32 & 0,23 & ST \\
\hline Eugenia myrcianthes Nied. & 1 & 0,20 & 0,15 & 0,32 & 0,22 & ST \\
\hline Guazuma ulmifolia Lam. & 1 & 0,20 & 0,12 & 0,32 & 0,21 & $P$ \\
\hline
\end{tabular}


Tabela 1 - Conclusão

\begin{tabular}{lcccccc}
\hline \multicolumn{1}{c}{ Espécies } & N. Ind. & DeR & DoR & FrR & IVI\% & GS \\
\hline Kielmeyera coriacea Mart. \& Zucc. & 1 & 0,20 & 0,12 & 0,32 & 0,21 & P \\
Annona crassiflora Mart. & 1 & 0,20 & 0,07 & 0,32 & 0,20 & P \\
Aspidosperma cuspa (Kunth) S.F. Blake ex Pittier & 1 & 0,20 & 0,08 & 0,32 & 0,20 & SI \\
Diospyros burchellii Hiern & 1 & 0,20 & 0,06 & 0,32 & 0,20 & $\mathrm{P}$ \\
Erythroxylum daphnites Mart. & 1 & 0,20 & 0,07 & 0,32 & 0,20 & ST \\
Inga cylindrical (Vell.) Mart. & 1 & 0,20 & 0,08 & 0,32 & 0,20 & $\mathrm{C}$ \\
Physocalymma scaberrimum Pohl & 1 & 0,20 & 0,07 & 0,32 & 0,20 & $\mathrm{P}$ \\
Rudgea viburnoides (Cham.) Benth. & 1 & 0,20 & 0,07 & 0,32 & 0,20 & SI \\
Schefflera morototoni (Aubl.) Maguire, Steyerm. \& Frodin & 1 & 0,20 & 0,08 & 0,32 & 0,20 & $\mathrm{P}$ \\
Tabebuia roseoalba (Ridl.) Sandwith & 1 & 0,20 & 0,08 & 0,32 & 0,20 & $\mathrm{P}$ \\
Byrsonima pachyphylla A. Juss. & 1 & 0,20 & 0,05 & 0,32 & 0,19 & $\mathrm{P}$ \\
Eugenia dysenterica DC. & 1 & 0,20 & 0,04 & 0,32 & 0,19 & $\mathrm{P}$ \\
Ocotea corymbosa (Meisn.) Mez & 1 & 0,20 & 0,05 & 0,32 & 0,19 & $\mathrm{ST}$ \\
Cupania vernalis Cambess. & 1 & 0,20 & 0,03 & 0,32 & 0,18 & SI \\
\hline
\end{tabular}

Fonte: Autores (2018)

Em que: $\mathrm{N}$. Ind = número de indivíduos, DeR = densidade relativa, DoR = dominância relativa, $\mathrm{FrR}=$ frequência relativa, IVI\% = índice de valor de importância, GS = grupo sucessional.

As espécies que apresentaram maiores valores de importância (VI\%) foram: Myracrodruon urundeuva (8,87\%); Myrsine gardneriana (6,83\%); Sclerolobium paniculatum (5,53\%); Licania apetala (5,34\%); Pera glabrata (4,61\%); Cordiera sessilis (4,56\%); Qualea grandiflora (3,94\%); Anadenanthera peregrina (3,75\%); Emmotum nitens (3,41\%); Terminalia glabrescens (3,28\%) e Xylopia aromatica (3,26\%) (Tabela 1), representando mais da metade do total de indivíduos e valor de importância (53,38\%). Já as famílias que apresentaram maior riqueza de espécies foram: Fabaceae (10), Rubiaceae (6), Anacardiaceae (5); Sapindaceae (4) e Myrtaceae (4), totalizando 42,7\% dos indivíduos amostrados.

Em A2, foram amostrados 412 indivíduos (1.373 ind/ha) distribuídos em 33 famílias e 61 espécies. A área basal total amostrada foi de 6,22 $m^{2}$ (20,73m²/ha). A maioria das espécies amostradas era secundária inicial ou pioneira, totalizando 75,36\% do valor total. Os índices de diversidade de Shannon $\left(\mathrm{H}^{\prime}\right)$ e de equitabilidade de Pielou 
(J) foram de 3,25 e 0,78, respectivamente. Por meio da construção da curva espécieárea, nota-se uma estabilização na riqueza nas parcelas localizadas a $60 \mathrm{~m}$ da borda com aumento no surgimento de novas espécies a de 70 m (Figura 2B).

As espécies que apresentaram maior densidade na A2 foram: Sclerolobium paniculatum (11,09\%), Qualea grandiflora (10,86\%), Tapirira guianenses (4,66\%), Myrcia splendens (7,10\%), Qualea parviflora. (3,99\%) e Terminalia argentea (3,33\%) (Tabela 2). Essas espécies foram responsáveis por 49\% da densidade total, 65 espécies contabilizaram menos de quatro indivíduos, 22 destas correspondendo apenas por um indivíduo e densidade relativa de 0,22\% (Tabela 2).

Tabela 2 - Lista florística e parâmetros fitossociológicos de espécies identificadas em um fragmento de floresta estacional semidecidual, denominado Área 2 (A2), na área de vegetação nativa da fazenda da Universidade Estadual de Goiás

\begin{tabular}{lcccccc}
\hline \multicolumn{1}{c}{ Espécies } & N. Ind. & DeR & DoR & FrR & IVI\% & GS \\
\hline Sclerolobium paniculatum Vogel & 50 & 11,09 & 0,06 & 8,08 & 12,61 & P \\
Qualea grandiflora Mart. & 50 & 11,09 & 0,2 & 8,46 & 10,13 & ST \\
Não identificadas & 22 & 4,37 & 3,34 & 4,22 & 3,97 & - \\
Xylopia aromatica Mart. & 52 & 11,53 & 0,03 & 8,85 & 8,85 & - \\
Tapirira guianensis Aubl. & 21 & 4,66 & 0,21 & 3,85 & 6,93 & P \\
Myrcia splendens (Sw). DC & 31 & 6,87 & 0,71 & 5,77 & 5,4 & P \\
Qualea parviflora Mart. & 18 & 3,99 & 0,26 & 4,62 & 4,24 & P \\
Terminalia argentea Mart. & 15 & 3,33 & 0,1 & 5,00 & 4,22 & SI \\
Emmotum nitens (Benth.) Miers & 13 & 2,88 & 0,14 & 3,08 & 3,95 & ST \\
Caryocar brasiliense Cambess & 11 & 2,44 & 0,92 & 3,08 & 3,78 & C \\
Virola sebifera Aubl. & 17 & 3,77 & 0,05 & 2,69 & 3,15 & P \\
Roupala montana Aubl. & 17 & 3,77 & 0,18 & 4,23 & 3,15 & ST \\
Maprounea guianensis Aubl. & 11 & 2,44 & 0,24 & 3,46 & 2,42 & SI \\
Matayba elaeagnoides Radl. & 8 & 1,77 & 0,09 & 2,69 & 1,79 & SI \\
Plathymenia reticulata Bentham & 6 & 1,33 & 5,81 & 1,54 & 1,19 & P \\
Qualea multiflora Martius & 4 & 0,89 & 0,18 & 0,77 & 1,13 & SI \\
Symplocos nitens (Pohl) Brnth. & 6 & 1,33 & 0,46 & 1,15 & 1,12 & SI \\
Annona coriacea Marc. & 4 & 0,89 & 0,06 & 1,54 & 1,04 & P \\
Byrsonima pachyphylla A. Juss & 4 & 0,89 & 0,09 & 1,54 & 0,87 & P \\
Bowdichia virgilioides Kunth & 2 & 0,44 & 0,40 & 0,77 & 0,71 & P \\
Vochysia rufa Mart. & 2 & 0,44 & 0,14 & 0,77 & 0,68 & P
\end{tabular}


Tabela 2 - Continuação

\begin{tabular}{|c|c|c|c|c|c|c|}
\hline Espécies & N. Ind. & DeR & DoR & FrR & IVI\% & GS \\
\hline Hirtella gracilipes Sprengel & 4 & 0,89 & 0,50 & 0,77 & 0,66 & SI \\
\hline Cordiera sessilis Kuntze & 3 & 0,67 & 0,04 & 0,77 & 0,63 & SI \\
\hline Hirtella glandulosa Sprengel & 3 & 0,67 & 0,47 & 0,77 & 0,62 & $\mathrm{SI}$ \\
\hline Erythroxylum daphnites Mart. & 3 & 0,67 & 0,00 & 0,77 & 0,59 & ST \\
\hline Kielmeyera coriacea Mart. \& Zucc. & 3 & 0,67 & 0,03 & 0,77 & 0,59 & $\mathrm{P}$ \\
\hline Copaifera langsdorffii Desf. & 2 & 0,44 & 0,05 & 0,77 & 0,57 & ST \\
\hline Lithraea molleoides (Vell.) Engl. & 3 & 0,67 & 0,15 & 0,38 & 0,51 & $\mathrm{C}$ \\
\hline Annona crassiflora Mart. & 2 & 0,44 & 0,10 & 0,77 & 0,49 & $P$ \\
\hline Alibertia edulis (Rich.) A. Rich. ex DC. & 2 & 0,44 & 5,90 & 0,77 & 0,47 & ST \\
\hline Leptolobium dasycarpum Vogel & 2 & 0,44 & 0,33 & 0,77 & 0,46 & $\mathrm{P}$ \\
\hline Lafoensia pacari A.St.-Hill & 2 & 0,44 & 0,41 & 0,77 & 0,45 & $P$ \\
\hline Diospyros burchellii Hiern & 2 & 0,44 & 0,33 & 0,77 & 0,45 & $\mathrm{P}$ \\
\hline Myracrodruon urundeuva Allemão & 2 & 0,44 & 0,33 & 0,77 & 0,44 & SI \\
\hline Diospyros hispida A.DC. & 2 & 0,44 & 0,15 & 0,77 & 0,44 & ST \\
\hline Aspidosperma tomentosum Mart. & 2 & 0,44 & 0,15 & 0,77 & 0,44 & $\mathrm{SI}$ \\
\hline Chrysophyllum marginatum Radl. & 2 & 0,44 & 0,48 & 0,77 & 0,43 & ST \\
\hline Siparuna guianensis Aubl & 3 & 0,67 & 0,10 & 0,38 & 0,40 & $P$ \\
\hline Machaerium brasiliensis Aubl. & 1 & 0,22 & 0,54 & 0,38 & 0,38 & SI \\
\hline Callisthene major Mart. & 3 & 0,67 & 1,37 & 0,38 & 0,38 & $\mathrm{SI}$ \\
\hline Cecropia pachystachya Trecul & 1 & 0,22 & 0,91 & 0,38 & 0,36 & $\mathrm{SI}$ \\
\hline Byrsonima spectabilis Turcz. & 2 & 0,44 & 0,03 & 0,38 & 0,36 & $\mathrm{SI}$ \\
\hline Rudgea viburnoides (Cham.) Benth. & 2 & 0,44 & 0,1 & 0,38 & 0,35 & $\mathrm{SI}$ \\
\hline Coccoloba mollis Casaretto & 1 & 0,22 & 3,56 & 0,38 & 0,34 & $\mathrm{SI}$ \\
\hline Anadenanthera colubrina (Vell.) Brenan & 1 & 0,22 & 7,73 & 0,38 & 0,28 & $\mathrm{SI}$ \\
\hline Anadenanthera peregrina (L.) Speg. & 1 & 0,22 & 0,05 & 0,38 & 0,27 & SI \\
\hline Casearia rupestris Eichler & 1 & 0,22 & 0,69 & 0,38 & 0,26 & $\mathrm{P}$ \\
\hline Astronium fraxinifolium Schott & 1 & 0,22 & 0,13 & 0,38 & 0,25 & SI \\
\hline Connarus suberosus Planch. & 1 & 0,22 & 10,85 & 0,38 & 0,25 & SI \\
\hline Platypodium elegans Vogel & 1 & 0,22 & 1,74 & 0,38 & 0,24 & SI \\
\hline Sclerolobium aureum (Tul.) Baill. & 1 & 0,22 & 4,12 & 0,38 & 0,24 & $P$ \\
\hline Machaerium acutifolium Vogel & 1 & 0,22 & 1,45 & 0,38 & 0,24 & $P$ \\
\hline Chrysophyllum gonocarpum Engler & 1 & 0,22 & 0,21 & 0,38 & 0,22 & $P$ \\
\hline Aegiphilla verticilata Velloso & 1 & 0,22 & 0,11 & 0,38 & 0,22 & $\mathrm{SI}$ \\
\hline Byrsonima laxiflora Griseb. & 1 & 0,22 & 18,67 & 0,38 & 0,22 & ST \\
\hline Diospyros brasiliensis Mart. & 1 & 0,22 & 0,15 & 0,38 & 0,22 & $\mathrm{SI}$ \\
\hline Piptocarpha rotundifolia G. Lom. Sm & 1 & 0,22 & 0,88 & 0,38 & 0,22 & $\mathrm{SI}$ \\
\hline Cordiera macrophylla Kuntze & 1 & 0,22 & 12,3 & 0,38 & 0,21 & $\mathrm{SI}$ \\
\hline
\end{tabular}


Tabela 2 - Conclusão

\begin{tabular}{lcccccc}
\hline \multicolumn{1}{c}{ Espécies } & N. Ind. & DeR & DoR & FrR & IVI\% & GS \\
\hline Dimorphandra mollis Bentham & 1 & 0,22 & 4,33 & 0,38 & 0,21 & P \\
Matayba guianensis Aubl. & 1 & 0,22 & 0,01 & 0,38 & 0,21 & SI \\
Alibertia sessilis (Vell.) K. Schum & 1 & 0,22 & 2,99 & 0,38 & 0,21 & $\mathrm{P}$ \\
Vatairea macrocarpa (Benth.) Ducke & 1 & 0,22 & 0,84 & 0,38 & 0,2 & $\mathrm{P}$ \\
\hline
\end{tabular}

Fonte: Autores (2018)

Em que: $\mathrm{N}$. Ind = número de indivíduos, DeR= densidade relativa, $\mathrm{DoR}=$ dominância relativa, FrR= frequência relativa, IVI\%= índice de valor de importância, GS= grupo sucessional.

As espécies que apresentaram maiores valores de importância (VI\%) foram: Sclerolobium paniculatum (12,38\%), Qualea grandiflora (10,18\%), Tapirira guianensis $(6,84 \%)$, Myrcia splendens (5,45\%), Xylopia aromatica (4,64\%), Qualea parviflora $(4,16 \%)$, Terminalia argentea (4,10\%), Emmotum nitens (3,95\%), Caryocar brasiliense $(3,80 \%)$ e Virola sebifera $(3,19 \%)$.

Cinco famílias botânicas se destacaram por apresentar maior distribuição na área. As famílias que apresentaram maior riqueza de espécies foram: Fabaceae (14), Vochysiaceae (5), Rubiaceae (5), Anacardiaceae (4), Annonaceae (3), Malpiguiaceae (3). As famílias Fabaceae, Vochysiaceae e Rubiaceae, nesta ordem, foram as mais representadas na área amostral, totalizando 249 indivíduos, mais da metade dos amostrados $(55,21 \%)$.

Baseando-se nas análises de similaridade, a Figura 2 demonstrou a curva de estabilização da área, bem como a distância da borda em que ocorrem mudanças na vegetação encontrada. A cor vermelha (Figura 2) indica parcelas que estavam mais próximas da borda, já a cor verde demonstra as parcelas localizadas no interior da floresta. A curva pontilhada segue o modelo de rarefação e o traço em negrito indica o ponto de observação do aumento abrupto na riqueza de espécies. Atingese a suficiência quando a curva tende à estabilidade e a adição de novas unidades amostrais não altera significativamente o número de espécies observadas, sendo sugerido que um aumento de $10 \%$ na área amostral resulte em um aumento de até 5\% em novas espécies (KERSTEN; GALVÃO, 2011). Nesse caso, observa-se que, na A1 
houve um acréscimo de $11 \%$ de espécies novas entre as parcelas localizadas a $40 \mathrm{~m}$ da borda para aquelas localizadas a $50 \mathrm{~m}$ (Figura 2A) e para a A2 houve um aumento de 16\% de espécies novas entre as parcelas localizadas a 70 e 80 m (Figura 2B) de distância da borda.

Figura 2 - Curva espécie-área de fragmento de duas florestas estacionais semideciduais a partir da borda do fragmento em Ipameri - GO

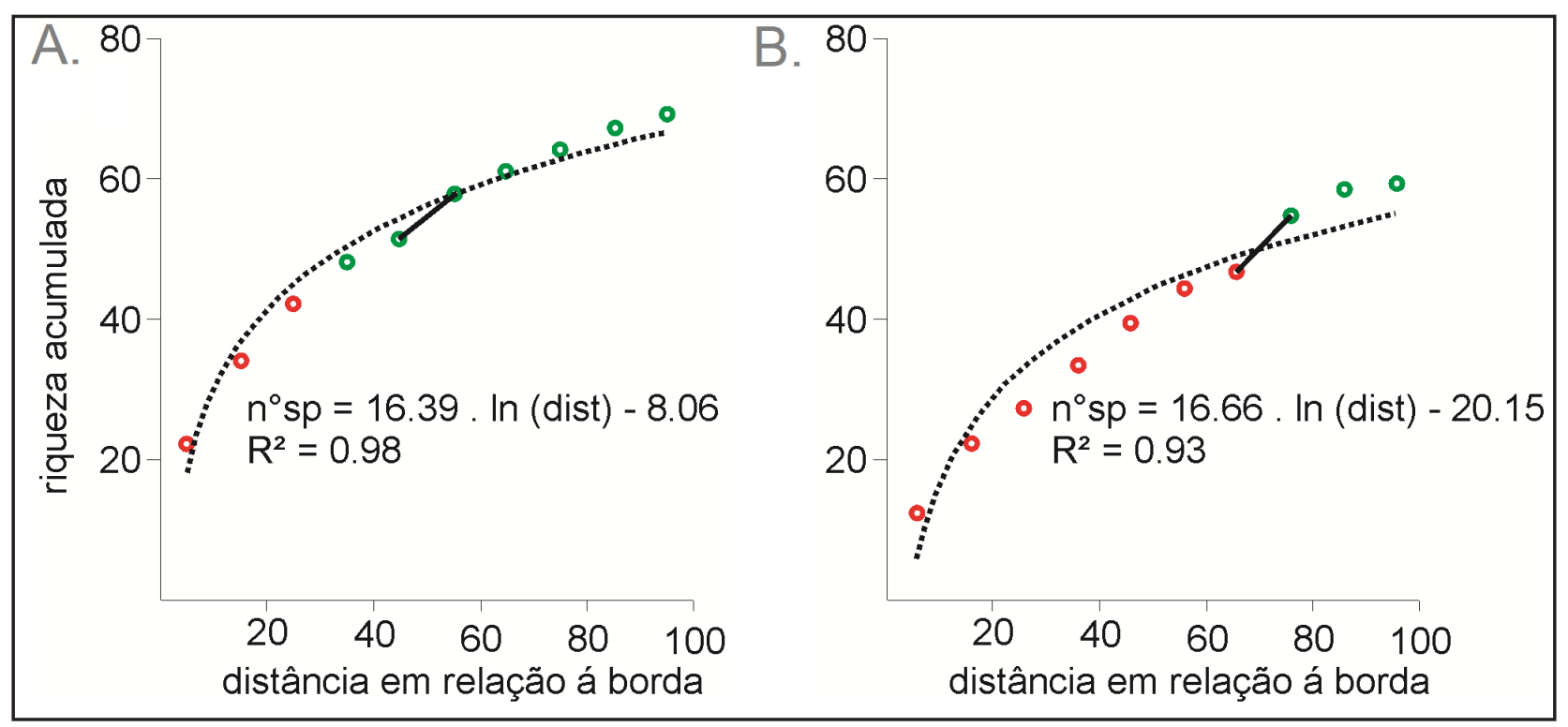

Fonte: Autores (2018)

Assim, na A1 ocorre mudança rápida de espécies após os $40 \mathrm{~m}$ iniciais e na A2 apenas após os $70 \mathrm{~m}$, o que provavelmente indica que o efeito de borda afeta a comunidade arbórea de cada fragmento com intensidades diferentes. Apesar de não ocorrer uma estabilização nítida, devido às características heterogêneas da floresta que, a cada parcela locada, apresentava uma nova espécie, houve uma tendência à estabilização. Isso demonstrou que a variabilidade florística foi bem amostrada (GONÇALVES; GONÇALVES; BUFFON, 2017).

A suficiência amostral para o número de indivíduos e área basal foi satisfatória em ambas as áreas. O erro admissível em A1 foi de 8,35\% para número de indivíduos e 17,57\% para área basal. Em A2, os cálculos indicaram erro admissível de 12,41\% para número de indivíduos e 14,53\% para área basal. $O$ alto valor aceitável para o erro 
admissível ( $E \% \leq 20)$ se deu em razão da heterogeneidade encontrada nos fragmentos e também devido à rica composição florística, característica de florestas com estádio de sucessão secundário, como neste estudo.

Apesar da certa proximidade (10 km de distância) entre os fragmentos e de se tratar da mesma fitofisionomia, algumas espécies como, Aegiphila verticillata, Agonandra brasiliensis e Guazuma ulmifolia estavam restritas à localidade amostrada. Do total de 129 espécies amostradas, apenas 32 foram encontradas em A1 e A2. 0 levantamento florístico evidenciou, portanto, uma elevada diversidade vegetativa nas florestas. Este fato também pode ser considerado um efeito da fragmentação, visto que as pressões exercidas sobre as florestas podem estar isolando as populações e dificultando a reprodução das espécies. Nesse caso, as espécies faunísticas podem ser aliadas para polinizarem e dispersarem as espécies vegetais e assim promover maiores interações entre os ecossistemas.

O número de espécies $\mathrm{H}^{\prime}$ e J' estão dentro dos padrões encontrados para Florestas Estacionais presentes no domínio dos cerrados (LOPES et al., 2012), o que prova a alta riqueza de espécies dentro de ambas as áreas, estabelecendo uma relação entre frequência e abundância, enquanto a equitabilidade estabelece uma maior uniformidade na distribuição dos indivíduos. Valores próximos de H' e J' foram encontrados por Lopes et al. (2011), analisando estudos realizados em dez florestas estacionais semideciduais, localizadas em cinco municípios no sudeste do Brasil. Segundo os mesmos autores, os valores de H' e J' estão atribuídos à heterogeneidade das vegetações, que permitem diferenças nos remanescentes e na composição florística.

Nas áreas amostradas, 93 espécies apresentaram baixa frequência relativa de espécie, entre um e cinco indivíduos, sumarizando 70,45\% do total e, portanto, são espécies pouco abundantes, sendo que 44 espécies apresentaram apenas um indivíduo cada. A pequena representatividade de indivíduos continua a reforçar a hipótese de que, anteriormente, as áreas sofreram perturbações e, atualmente, estão se regenerando. Ainda que tenham sido registrados poucos indivíduos, valores de abundância encontrados em florestas estacionais da Bacia do Paraná (LOPES et al., 2012), localizada a menos de $150 \mathrm{~km}$ da região deste estudo, estiveram próximos aos encontrados aqui, o que sugere estudos mais aprofundados para caracterizar o grau 
de antropização das florestas na região Centro-Oeste/Sudeste do Brasil.

As famílias com maior número de espécies foram as mesmas descritas em estudos com florestas estacionais semideciduais realizados em Uberlândia (PRADO JÚNIOR et al., 2010) e Cuiabá (FINGER; FINGER, 2015). Entre a Mata Atlântica e a Floresta Amazônica, estende-se uma larga faixa diagonal de formações vegetais abertas e complexas, com espécies características, representada pela caatinga (Nordeste), pelo Cerrado (Centro-Oeste e Sudeste) e pela vegetação variada do Pantanal MatoGrossense (IBGE, 2012). Como as FES estão nesta faixa de formações vegetais, é comum que ocorram espécies e famílias comuns a outras regiões, elevando a riqueza local.

Através de levantamentos florísticos, foi possível indicar se as florestas já sofreram perturbações antrópicas. Florestas perturbadas formam uma vegetação regenerante secundária, o que interfere na diversidade florística e na dinâmica florestal. Nas áreas amostradas neste estudo, boa parte da vegetação encontrada era regenerante, o que explica as maiores ocorrências de espécies secundárias iniciais e pioneiras (Tabelas 1 e 2), e indica que as áreas já estiveram/estão sobre influências de perturbações. Essas perturbações formam ambientes heterogêneos, que contam com a presença de diferentes espécies e em diferentes estádios, bem como alteram os valores fitossociológicos locais. Além disso, espécies típicas de cerrado, como Dimorphandra mollis, Curatella americana, Qualea grandiflora, Plathymenia reticulata, Annona coriácea, foram recorrentemente amostradas.

O dendrograma gerado em A1 para as duas similaridades (Coeficiente de Sørensen e Índice de Bray \& Curtis), apresentou diferenciação entre parcelas de 0 a 30 $m$ das parcelas e de 40 a $100 \mathrm{~m}$ de distância da borda. Em A2, os grupos de distribuição foram de 0 a $60 \mathrm{~m}$ da borda, e de 70 a $100 \mathrm{~m}$, também nos dois índices analisados. 0 efeito de borda foi, portanto, aferido, baseando-se nas diferenças florístico-estruturais para essas duas florestas estacionais. Nem sempre é possível aferir o efeito de borda (FERREIRA et al., 2016). Entretanto, esta metodologia permitiu analisar em quantos metros o efeito de borda interferiu na composição florística e densidade de indivíduos das espécies, em direção ao interior da floresta. Este estudo demonstrou que o efeito de borda parece atingir até, pelo menos, 30 metros adentro das florestas.

Através dos dendrogramas, notou-se distinção entre as duas áreas, em razão da 
divisão dos grupos (2 grupos), que foram diferenciados pela distância que os grupos ficaram da borda. A provável divisão seria a alteração na estrutura florística por excesso de luz e temperatura e menor taxa de umidade relativa (BATAGHIN; PIRES; BARROS, 2012). Em A1, o efeito de borda foi mais pronunciado a até $30 \mathrm{~m}$ (Figura 3A e 3B). Após os 30 metros, notou-se que o interior da floresta fica mais protegida e menores são os efeitos da pressão externa no fragmento florestal. Já em A2, notou-se que o efeito de borda influenciou a similaridade florística até os $70 \mathrm{~m}$ (Figura 3C e 3D). Levando em consideração a distinção florística local, ainda que as espécies encontradas fossem menos tolerantes à exposição e fatores abióticos, como a intensidade de luz (BATAGHIN; PIRES; BARROS, 2012), o efeito de borda atingiu a floresta em até $70 \mathrm{~m}$ do seu interior.

Figura 3 - Dendrograma gerado utilizando os dados das parcelas nos fragmentos de floresta estacional semidecidual da Área 1 (a-b) e Área 2 (c-d) através do coeficiente de similaridade de Sørensen e o Índice de Bray \& Curtis

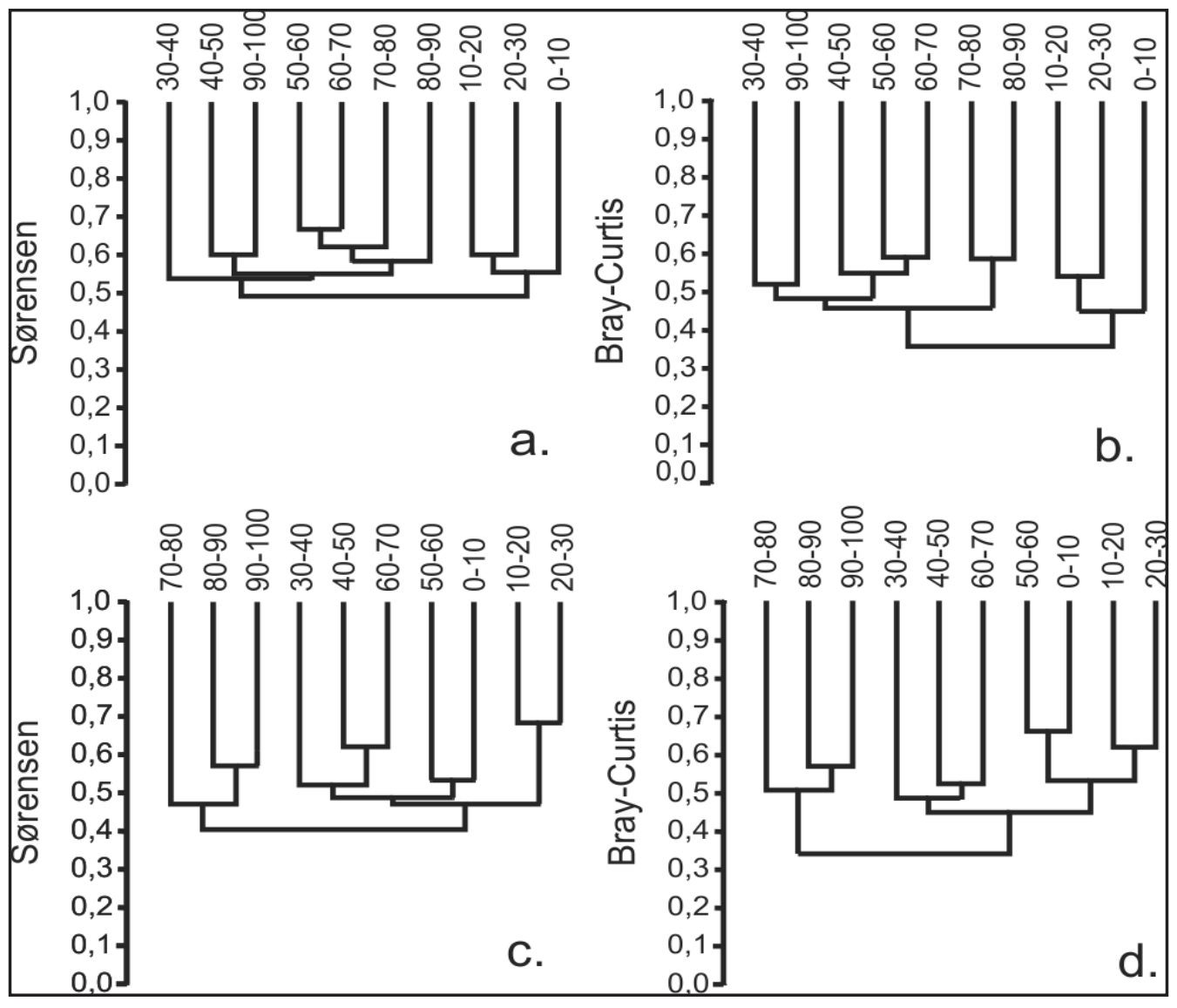

Fonte: Autores (2018) 
As medições das variáveis abióticas com o termo-higroanemômetro-luxímetro digital na área 2 demonstraram maiores temperaturas, velocidade do vento e luminosidade na estação seca e maiores umidades na estação chuvosa. Velocidade do vento e intensidade luminosa apresentaram alta variação dos dados, demonstrados pelo alto valor de coeficiente de variação (CV - Tabela 3). Foi possível perceber também mudanças nas variáveis à medida que se adentrava o fragmento (Figura 4).

Tabela 3 - Parâmetros referentes ao fragmento 2, na estação seca e chuvosa

\begin{tabular}{|c|c|c|c|c|c|}
\hline & & Temp $\left({ }^{\circ} \mathrm{C}\right)$ & Umid (\%) & Vento $(\mathrm{km} / \mathrm{h})$ & Luz (Lux) \\
\hline \multirow{5}{*}{ 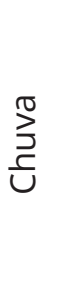 } & $\overline{\mathrm{X}}$ & 29,04 & 70,30 & 0,07 & 2990,99 \\
\hline & DP & 0,18 & 0,36 & 0,07 & 633,62 \\
\hline & CV & 0,61 & 0,51 & 102,75 & 21,18 \\
\hline & $\mathrm{F}$ & 103,91 & 0,88 & 0,02 & 9,19 \\
\hline & $p$ & $<0,001$ & 0,375 & 0,897 & 0,016 \\
\hline \multirow{5}{*}{ 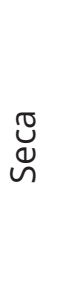 } & $\bar{x}$ & 35,54 & 20,05 & 0,56 & 4507,42 \\
\hline & DP & 0,58 & 1,31 & 0,24 & 3482,94 \\
\hline & $C V$ & 1,64 & 6,51 & 43,00 & 77,27 \\
\hline & $\mathrm{F}$ & 313,55 & 31,57 & 6,13 & 31,07 \\
\hline & $\mathrm{p}$ & $<0,001$ & $<0,001$ & 0,038 & 0,001 \\
\hline
\end{tabular}

Fonte: Autores (2018)

De modo geral, principalmente a umidade relativa, temperatura e luz foram as variáveis que mais sofreram influências da distância em relação à borda. A temperatura na estação chuvosa e mais fortemente na seca (Figura 4A e 4B) foram inferiores mais ao interior da floresta em ambas as estações. O mesmo ocorreu para o índice de luminosidade, porém confirmado estatisticamente apenas para a estação seca (Figura 5G e 5H), no entanto o melhor modelo ajustado foi logarítmico para a estação seca. A umidade apresentou maiores variações na época seca, mas em ambas as estações, as medições apresentaram maiores valores no interior do fragmento (Figura 4C e 4D). Isso explica o fato de que uma menor densidade de espécies arbóreas clímax, com maiores circunferências de tronco, foi registrada no interior da floresta. Principalmente 
em razão do aumento da intensidade da luz e de temperatura no ambiente e no solo, algumas espécies clímax podem não sobreviver aos efeitos deletérios gerados. Nas bordas, foi verificado um número maior de espécies pioneiras e secundárias iniciais, com troncos de circunferências mais delgados, evidenciando maiores taxa de recrutamento.

Figura 4 - Análise de regressão das variáveis medidas com a distância da borda. 4A: temperatura na estação chuva x distância da borda; 4B: temperatura na estação seca x distância da borda; 4C: umidade na estação chuvosa x distância da borda; 4D: umidade na estação seca x distância da borda

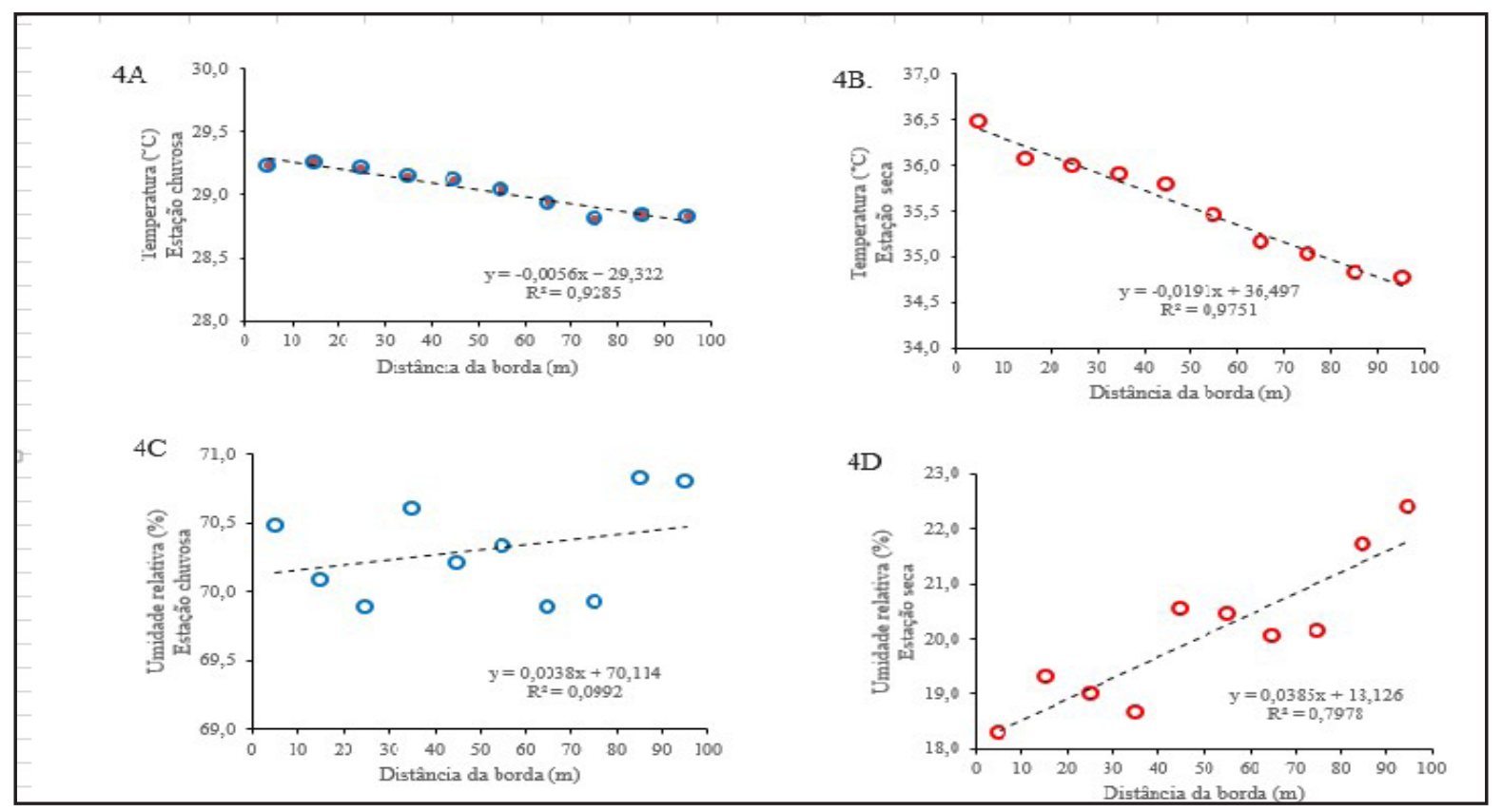

Fonte: Autores (2018)

O vento também seguiu o padrão de alterações e, especialmente na seca, apresentou maiores valores (Figura 5F). O vento representa um fator crítico que pode impossibilitar o crescimento pleno das espécies da borda, por causar danos físicos, como quebra dos galhos, brotações e perda excessiva de folhas. No interior das florestas, a turbulência dos ventos também pode ocasionar queda dos indivíduos arbóreos clímax, aumento das taxas de mortalidade e abertura de clareiras, favorecendo espécies heliófitas. Logo, as consequências decorrentes da 
fragmentação avançam para o interior da floresta e seus efeitos podem atingir a vegetação local como um todo.

Figura 5 - Análise de regressão das variáveis medidas com a distância da borda. 5E: vento na estação chuva $x$ distância da borda; $5 \mathrm{~F}$ : vento na estação seca $\mathrm{x}$ distância da borda; 5G: intensidade luminosa na estação chuvosa x distância da borda; 5H: intensidade luminosa na estação seca $x$ distância da borda

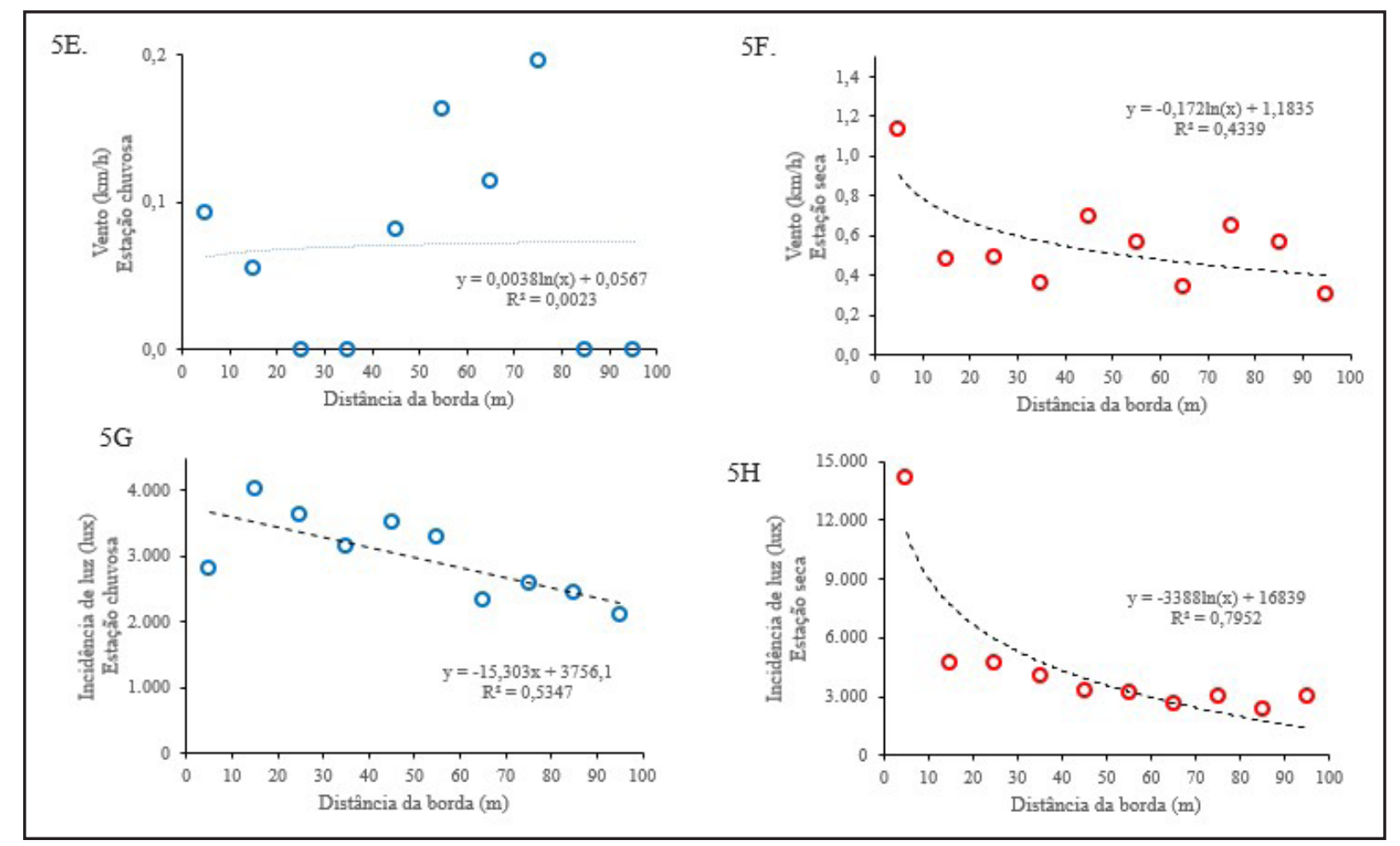

Fonte: Autores (2018)

Pscheidt et al. (2018), trabalhando em floresta com araucárias em Santa Catarina, também apontaram influências diretas das variáveis climáticas (umidade, radiação solar e sombra), encontrando efeitos de borda a 50 m, em direção ao interior da floresta. Outros estudos observaram efeitos de borda em até $40 \mathrm{~m}$ de distância da borda e, dependendo de fatores como estresse hídrico da região (SAMPAIO; SCARIOT, 2011), esse efeito pode chegar até $60 \mathrm{~m}$. As variações causadas pela fragmentação florestal podem ocorrer, por exemplo, por fatores como a declividade do terreno, que pode modificar a estrutura e abrangência florística (SALOMÃO; SILVA; MACHADO, 2018) ou ainda a influência das matrizes em que as florestas estão inseridas. 


\section{CONCLUSÕES}

O efeito de borda afetou as comunidades arbóreas e foi variável nas duas áreas analisadas, chegando a até $30 \mathrm{~m}$ em uma floresta e a até $70 \mathrm{~m}$ na outra. Foi encontrada grande quantidade de espécies regenerantes nas duas áreas, sendo reflexo dos efeitos das perturbações sofridas, que permitem a presença de espécies típicas de cerrado no interior e, principalmente, na borda dos fragmentos. A umidade relativa, intensidade luminosa, temperatura e velocidade dos ventos foram os fatores abióticos que apresentaram variações ao longo da floresta, indicando que há alterações no fragmento $A 2$, o que, consequentemente, também traz modificações para o biossistema da floresta. Devido a esta variação, novos estudos devem ser realizados para que se possa aferir com maior precisão até onde o efeito de borda interfere na comunidade arbórea.

\section{AGRADECIMENTOS}

Os autores agradecem ao Conselho Nacional de Desenvolvimento Científico e Tecnológico (CNPq) pelo apoio financeiro, processo 430469/2018-7.

\section{REFERÊNCIAS}

ABDO, M. T. V. N.; VALERI, S. V.; FERRAUDO, A. S. Avaliação do efeito de borda da Reserva Biológica de Pindorama, SP. Revista Verde de Agroecologia e Desenvolvimento Sustentável, Pombal, v. 10, n. 4, p. 1-7, 2015.

ALMEIDA, C.; VIANI, R. A. G.; BRANCALION, P. H. S. Competição por recursos entre um trepadeira (Calopogonium mucunoides Desv.) e uma árvore (Guazuma ulmifolia Lam.): implicações para o manejo de fragmentos de Floresta Estacional Semidecidual degradados. RevistaCiência, Tecnologia\&Ambiente, Araras, v. 4, n. 1, p. 30-37, 2017.

ALVARES, C. A. et al. Koppen's climate classification map for Brazil. Meteorologische Zeitschrift, Stuttgart, v. 22, n. 6, p. 711-728, 2014.

BATAGHIN, F. A.; PIRES, J. S. R.; BARROS, F. Epifitismo vascular em sítios e borda e interior em Floresta Estacional Semidecidual no Sudeste do Brasil. Hoehnea, São Paulo, v. 39, n. 2, p. 235245, 2012. 
BLUMENFELD, E. C. et al. Relações entre o tipo de vizinhança e efeitos de borda em fragmento florestal. Ciência Florestal, Santa Maria, v. 26, n. 4, p. 1301-1316, 2016.

BIONDI, D.; BOBROWSKI, R. Utilização de índices ecológicos para análise do tratamento paisagístico arbóreo dos parques urbanos de Curitiba-PR. Enciclopédia Biosfera, Jandaia, v. 10, n. 18, p. 3006-3017, 2014.

CHASE, M. W. et al. An update of the Angiosperm Phylogeny Group classification for the orders and families of flowering plants: APG IV. Botanical Journal of the Linnean Society, Oxford, v. 181, n. 1, p. 1-20, 2016.

COSTA, L. C. B.; GUASSELLI, L. A. Dinâmica sazonal de remanescentes da Mata Atlântica, a partir de séries temporais NDVI/MODIS. Geo UERJ, Rio de Janeiro, v. 1, n. 30, p. 214-239, 2017.

FERREIRA, T. S. et al. Composição florístico-estrutural ao longo de um gradiente de borda em fragmento de Floresta Ombrófila Mista Alto-Montana em Santa Catarina. Ciência Florestal, Santa Maria, v. 26, n. 1, p. 123-134, 2016.

FINGER, Z.; FINGER, F. A. Fitossociologia em comunidades arbóreas remanescentes de Cerrado sensu stricto no Brasil Central. Revista Floresta, Curitiba, v. 45, n. 4, p. 769-780, 2015.

GONÇALVES, R. N.; GONÇALVES, J. R. S. N.; BUFFON, M. C. M. Metodologia e suficiência amostral em estudos etnobotânico e etnofarmacológicos: relato de experiência. Visão Acadêmica, Curitiba, v. 18, n. 4, p. 14-24, 2017.

HADDAD, N. M. et al. Habitat fragmentation and its lasting impact on Earth's ecosystems. Science Advances, New York, v. 1, n. 2, p. 1-9, 2015.

HAMMER, O. PAST: Paleontological Statistics Software Package for Education and Data Analysis. Oslo: [s. n.], 2019. 275 p.

IBGE. Manual técnico da vegetação brasileira: sistema fitogeográfico, inventário das formações florestais e campestres, técnicas e manejo de coleções botânicas, procedimentos para mapeamentos. Rio de Janeiro, 2012. 92 p.

KERSTEN, R. A.; GALVÃO, F. Suficiência amostral em inventários florísticos e fitossociológicos. In: FELFILI, J. M. et al. Fitossociologia no Brasil: métodos e estudos de casos. 1. ed. Viçosa, MG: Editora UFV, 2011. v. 1. p. 156-173.

LAGOS, M. D. C. C. Efeito de borda em fragmentos do bioma Cerrado e Mata Atlântica. 2017. Tese (Doutorado em Ciências Ambientais) - Universidade Federal de Goiás, Goiânia, 2017.

LAURANCE, W. F. et al. Ecosystem decay of Amazonian forest fragments: a 22-year investigation. Conservation Biology, Germantown, v. 16, n. 3, p. 605-618, 2002.

LAURANCE, W. F. et al. The fate of Amazonian forest fragments: A 32-year investigation. Biological Conservation, Cairns, v. 144, n. 1, p. 56-67, 2011. 
LIMA, M. S. C. S.; SOUZA, C. A. S.; PEDERASSI, J. Qual índice de diversidade usar? Caderno UniFOA, [s. I.], v. 1, n. 30, p. 129-138, 2016.

LOPES, S. F. et al. Análise comparativa da estrutura e composição florística de Cerrado no Brasil central. Interciência, Santiago, v. 36, n. 1, p. 8-15, 2011.

LOPES, S. F. et al. An Ecological Comparison of Floristic Composition in Seasonal Semideciduous Forest in Southeast Brazil: Implications for Conservation. International Journal of Forestry Research, London, v. 2012, p. 1-14, 2012.

MAGNAGO; L. F. S. et al. Efeito de borda na funcionalidade dos grandes fragmentos de floresta de tabuleiro do norte do Espírito Santo. In: ROLIM, S. G.; MENEZES, L. F. T.; ARAUJO, A. C. S. Floresta Atlântica de tabuleiro: diversidade e endemismos na Reserva Natural Vale. 2. ed. Linhares: Editora Rupestre, 2016. v. 1. p. 129-140.

OLIVEIRA, C. V. et al. O. Efeito de borda e decomposiçãoo da serapilheira foliar de um fragmento florestal, em Vitória da Conquista-BA. Enciclopédia Biosfera, Jandaia, v. 9, n. 17, p. 1150-1161, 2013.

PEREIRA, B. A. S.; VENTUROLI, F.; CARVALHO, F. A. Florestas Estacionais no Cerrado: uma visão geral. Pesquisa Agropecuária Tropical, Goiânia, v. 41, n. 3, p. 446-455, 2011.

PRADO JÚNIOR, J. A. et al. Estrutura da comunidade arbórea em um fragmento de floresta estacional semidecidual localizada na reserva legal da Fazenda Irara, Uberlândia, MG. Bioscience Journal, Uberlândia, v. 26, n. 4, p. 638-647, 2010.

SCHILLING, A. C.; BATISTA, J. L. F.; COUTO, H. Z. Ausência de estabilização da curva de acumulação de espécies em Florestais Tropicais. Ciência Florestal, Santa Maria, v. 22, n. 1, p. 101-111, 2012.

PSCHEIDT, F. et al. Efeito de borda como fonte da heterogeneidade do componente arbóreo em uma floresta com araucárias no Sul do Brasil. Ciência Florestal, Santa Maria, v. 28, n. 2, p. 601-612, 2018.

RIGUEIRA, D. M. G. et al. Influência da distância da borda e do adensamento foliar sobre a abundância de plantas pioneiras em um fragmento de floresta tropical submontana na Estação Ecológica de Wenceslau Guimarães (Bahia, Brasil). Acta Botanica Brasilica, Belo Horizonte, v. 26, n. 1, p. 202-2012, 2012.

SALOMÃO, N. V.; SILVA, M. D. D.; MACHADO, E. L. M. Dynamics ofvegetationstructure in a fragmentedlandscape in Minas Gerais, Brazil. Brazilian Journal of Biology, São Carlos, v. 1, p. $1-8,2018$.

SAMPAIO, A. B.; SCARIOT, A. Edge effect on tree diversity, composition and structure in a deciduos dry forest in central Brazil. RevistaÁrvore, Viçosa, MG, v. 35, n. 5, p. 1121-1134, 2011.

SANTOS, H. G. et al. Sistema Brasileiro de Classificação do Solo. 5. ed. Brasília: Embrapa Solos, 2018. 355 p.

SEOANE, C. E. et al. Corredores ecológicos como ferramenta para a desfragmentação de florestas tropicais. Pesquisa Florestal Brasileira, Colombo, v. 30, n. 63, p. 207-216, 2010. 


\section{Contribuição de Autoria}

\section{1 - Vanuza Pereira Garcia da Silva}

Engenheira Florestal

https://orcid.org/0000-0001-8003-681X·garciavp@outlook.com

Contribuição: Conceituação, Curadoria de dados, Metodologia, Escrita - revisão e edição, Software, Supervisão, Validação

\section{2 - Gabriel Venâncio Pereira Mariano}

Engenheiro Florestal

https://orcid.org/0000-0002-2418-951X·gabrielvenancio_@outlook.com

Contribuição: Visualização de dados, Software, Escrita - revisão e edição, Supervisão, Validação

\section{3 - Ana Flávia Costa Santos}

Engenheira Florestal, Mestranda em Ciências Florestais https://orcid.org/0000-0002-1010-348X·csanaflavia@outlook.com Contribuição: Escrita - primeira redação, Software, Supervisão, Validação

\section{4 - Lilian Cristina da Silva Santos}

Bióloga, Mestre em Produção Vegetal https://orcid.org/0000-0002-6827-2438•lilianCristina_2011@ @hotmail.com Contribuição: Análise Formal, Investigação, Escrita - revisão e edição, Software, Supervisão, Validação

\section{5 - João Paulo Costa}

Biólogo, Doutorando em Ecologia e Conservação de Recursos Naturais https://orcid.org/0000-0001-5271-8231•joaopaulo_mc@hotmail.com Contribuição: Análise Formal, Investigação, Escrita - revisão e edição, Software, Supervisão, Validação

\section{6 - Ana Carolina Ribeiro Vaz}

Engenheira Florestal https://orcid.org/0000-0002-8156-9455 • anavazuegflorestal@gmail.com Contribuição: Metodologia, Escrita - primeira redação, Escrita - revisão e edição, Software, Supervisão, Validação 


\section{7 - Vagner Santiago do Vale}

Biólogo, Dr., Professor

https://orcid.org/0000-0003-2155-9156•vsvale@hotmail.com

Contribuição: Obtenção de financiamento, Administração do projeto, Recursos, Software, Supervisão, Validação, Escrita - revisão e edição, Validação

\section{8 - Ednaldo Cândido Rocha}

Biólogo, Dr., Professor

https://orcid.org/0000-0002-2554-777X•ednaldo.rocha@ueg.br

Contribuição: Software, Escrita - revisão e edição, Supervisão, Validação

\section{Como citar este artigo}

Silva, V. P. G.; Mariano, G. V. P.; Santos, A. F. C.; Santos, L. C. S.; Costa, J. P.; Vaz, A. C. R.; Vale, V. S.; Rocha, E. C. Estrutura da comunidade arbórea e efeito de borda em Florestas Estacionais Semideciduais. Ciência Florestal, Santa Maria, v. 31, n. 3, p. 1216-1239, 2021. DOI 10.5902/1980509836234. Disponível em: https://doi.org/10.5902/1980509836234. Acesso em: xx mês-abreviado. 2021. 